\title{
Overweight children overeat after exposure to food cues
}

Citation for published version (APA):

Jansen, A. T., Theunissen, N. C., Slechten, K., Nederkoorn, C., Boon, B., Mulkens, S., \& Roefs, A. J. (2003). Overweight children overeat after exposure to food cues. Eating Behaviors, 4(2), 197-209. https://doi.org/10.1016/S1471-0153(03)00011-4

Document status and date:

Published: 01/01/2003

DOI:

10.1016/S1471-0153(03)00011-4

Document Version:

Publisher's PDF, also known as Version of record

Document license:

Taverne

Please check the document version of this publication:

- A submitted manuscript is the version of the article upon submission and before peer-review. There can be important differences between the submitted version and the official published version of record.

People interested in the research are advised to contact the author for the final version of the publication, or visit the DOI to the publisher's website.

- The final author version and the galley proof are versions of the publication after peer review.

- The final published version features the final layout of the paper including the volume, issue and page numbers.

Link to publication

\footnotetext{
General rights rights.

- You may freely distribute the URL identifying the publication in the public portal. please follow below link for the End User Agreement:

www.umlib.nl/taverne-license

Take down policy

If you believe that this document breaches copyright please contact us at:

repository@maastrichtuniversity.nl

providing details and we will investigate your claim.
}

Copyright and moral rights for the publications made accessible in the public portal are retained by the authors and/or other copyright owners and it is a condition of accessing publications that users recognise and abide by the legal requirements associated with these

- Users may download and print one copy of any publication from the public portal for the purpose of private study or research.

- You may not further distribute the material or use it for any profit-making activity or commercial gain

If the publication is distributed under the terms of Article $25 \mathrm{fa}$ of the Dutch Copyright Act, indicated by the "Taverne" license above, 


\title{
Overweight children overeat after exposure to food cues
}

\author{
Anita Jansen*, Nicole Theunissen, Katrien Slechten, Chantal Nederkoorn, \\ Brigitte Boon, Sandra Mulkens, Anne Roefs
}

\author{
Experimental Psychopathology, Faculty of Psychology, Maastricht University, P.O. Box 616, \\ 6200 MD Maastricht, The Netherlands
}

\begin{abstract}
Overweight is becoming more common in children, but we know nearly nothing about the eating behavior of overweight children. Learning theory predicts that overeating follows from learned associations between the smell and taste of palatable food on the one hand and intake on the other hand. It was tested whether overweight children overeat after confrontation to these cues. They indeed failed to regulate food intake after both the exposure to the intense smell of tasty food (without eating it) and after eating a small preload of appetizing food, whereas normal-weight children decreased their intake after both cues. Overweight children are thus more vulnerable to triggers of overeating. Their overeating was not related to psychological factors like mood, body esteem, and a restrained eating style, but it was related to cue-elicited salivation flow. Apart from supporting the cue reactivity model of overeating, the data point to an interesting satiety phenomenon in normal eaters after prolonged and intense smelling palatable food without eating it.
\end{abstract}

(C) 2003 Elsevier Science Ltd. All rights reserved.

Keywords: Overweight children; Overeating; Exposure; Cue reactivity; Restraint

\section{Introduction}

Obesity is a major health problem and its prevalence is rising, not only in the United States but also in the Netherlands; about $40 \%$ of the Dutch adults is overweight or obese now (Visscher, Kromhout, \& Seidell, 2002). Moreover, the prevalence of Dutch overweight children increased from 9.5\% in 1980 to $13.5 \%$ in 1997 (Hirasing, Fredriks, van Buuren, Verloove-Vanhorick, \& Wit, 2001). The risk of being an obese adult is significantly higher for

* Corresponding author. Tel.: +31-43-388-1910; fax: +31-43-388-4196.

E-mail address: a.jansen@psychology.unimaas.nl (A. Jansen). 
overweight children than for their nonoverweight counterparts (Dietz, 1995), implicating that the prevention of adult obesity should start in childhood. However, little is known about the eating behavior of overweight children. Laessle, Uhl, and Lindel (2001) found that the presence of the child's mother led to faster eating in overweight children as compared to normal-weight children, whereas in the absence of their mother, the speed of eating was the same in overweight and normal-weight children. The authors argue that instrumental learning principles might be responsible for the overeating of overweight children in the presence of their mothers; a parent giving frequent prompts to eat in order to get the plate empty lowers the self-control of overweight children and increases their caloric intake in that way.

When parents prompt their children to eat when food is available, classically conditioned associations between cues that predict food intake and actual eating behavior will be strong. The classical conditioning model of overeating states that after systematic association of cues with food intake, the cues will reliably signal the food effects such as increased blood sugar and salivary flow (Jansen, 1998). The moment the cues are good predictors of intake, they acquire the ability to elicit physiological responses that are useful for digestion (e.g., salivation and insulin responses), which is called cue reactivity. That physiological cue reactivity is supposed to be experienced as appetite or craving and increases the likelihood of food intake (Jansen, 1998). The predictive cues often are directly related to food intake (such as the smell and taste of food), but they might also be contextual (e.g., home, company) or interoceptive (e.g., feelings, cognitions). Indeed, a large number of studies showed that the physiological responses brought about by food intake, e.g., insulin release, blood sugar increase, and salivation, can be brought under the control of any stimulus predictive of food intake, like odors, sounds, time of the day, eating-related situations, seeing, smelling, tasting, and even thinking of food (Nederkoorn, Smulders, \& Jansen, 2000; Rodin, 1985; Wardle, 1990; Woods, 1991), and some recent studies support the idea of cue reactivity in binge eaters and obese people as a method of priming the body to absorb and use the nutrients to ingest (Karhunen, Lappalainen, Vanninen, Kuikka, \& Uusitupa, 1997; Mattes, 1997; Vögele \& Florin, 1997). Furthermore, mere exposure to cues that typically predict food intake, i.e., the taste or smell of tasty food, led to overeating in people that tried to restrain their food intake (Fedoroff, Polivy, \& Herman, 1997; Jansen \& van den Hout, 1991; Rogers \& Hill, 1989).

Classically conditioned associations between cues that predict food intake and actual eating behavior might be stronger in overweight than in normal-weight children since parents of overweight children more frequently prompt their children to eat their plate empty (Laessle et al., 2001) and overweight children show higher external eating styles, meaning that their intake is more often triggered by food cues like seeing or smelling food (Braet \& van Strien, 1997). Both increase the probability that a food cue is followed by food intake, which strengthens the bond between cues and intake and makes smell and taste more predictive of intake in overweight than in normal-weight children.

If associations between cues predicting food intake and actual eating are stronger in overweight than in normal-weight children, overweight children will show more cue reactivity and caloric overconsumption after confrontation with food cues than normalweight children. In the present study, it was predicted that overweight children report more appetite and hunger and show increased salivary flow-as an objective index of appetite/ 
hunger-after confrontation with cues that elicit appetite (eating a tasty preload, smelling tasty food) than normal-weight children. It was also expected that the exposure to food cues leads to increased caloric intake in the overweight children, and that increased cue reactivity (appetite/hunger/salivation) and increased food intake are related. Because current models of overeating stress the importance of restraint, low body esteem, and mood as triggers of disinhibited eating (e.g., Fairburn, Marcus, \& Wilson, 1993; Rosen, 1996; Wegner et al., 2002), we also explored whether restraint, body esteem, and mood play a role in the overeating of overweight children.

\section{Method}

\subsection{Design}

Overweight and normal-weight children between 8 and 12 years participated three times in a taste test: after the consumption of an appetizing preload (preload condition), after the intense smelling of tasty food (exposure condition), and after playing without food confrontation (control condition). The order of conditions was counterbalanced and for each participant there was a 1-week gap between conditions. Main dependent variable was caloric intake during the taste test. Also, salivary flow and self-reported mood, appetite, and hunger were measured before and after the manipulations.

\subsection{Participants}

Advertisements in local newspapers asked for normal-weight and overweight children between 8 and 12 years old to participate in a threefold taste test. They were told that the goal of the experiment was to determine the stability of taste perception. Participants were 17 boys and 14 girls. By using the Dutch weight-height tables of Van Wieringen and Roede (1985), it was determined whether the child was either normal weight or overweight. Participants with a weight equal to or higher than the 90th percentile for their height and gender were categorized as overweight ( 7 boys and 9 girls), whereas participants with a weight lower than the 90th percentile for their height and gender were categorized as normal weight (10 boys and 5 girls). Participant characteristics are given in Table 1.

\subsection{Assessment}

\subsubsection{Cue reactivity}

Cue reactivity was defined as increased appetite (how much do you like to eat something tasty now), increased hunger (how hungry are you now), and increased salivation response. Appetite and hunger were measured on nine-point scales. The meaning of five cartoon faces was explained; the first face reflected someone who is very sad, the next face was a bit sad, the next one had a neutral expression, the next face was happy, the last face reflected someone who is very happy. The participants could also rate in between two faces, resulting in a nine- 
Table 1

Participant characteristics

\begin{tabular}{|c|c|c|c|c|}
\hline & \multirow{2}{*}{$\frac{\text { Normal weight subjects }(n=15)}{\text { Mean (S.D.) }}$} & \multirow{2}{*}{$\frac{\text { Overweight subjects }(n=16)}{\text { Mean (S.D.) }}$} & \multirow[t]{2}{*}{$t(29)$} & \multirow[t]{2}{*}{$P$} \\
\hline & & & & \\
\hline Age (year) & $10.0(1.5)$ & $9.6(1.2)$ & 0.8 & NS \\
\hline $\mathrm{BMI}^{\mathrm{a}}$ & $16.8(1.9)$ & $23.3(3.7)$ & 6.1 & $<.001$ \\
\hline Body esteem ${ }^{\mathrm{b}}$ & $19.7(3.7)$ & $15.6(5.1)$ & 2.5 & $<.05$ \\
\hline EDE-restraint child ${ }^{\mathrm{c}}$ & $0.29(0.5)$ & $0.99(1.1)$ & 2.2 & $<.05$ \\
\hline EDE-restraint parent ${ }^{\mathrm{d}}$ & $0.23(0.3)$ & $0.88(0.9)$ & 2.7 & $<.05$ \\
\hline
\end{tabular}

${ }^{\mathrm{a}} \mathrm{BMI}=$ body mass index $=$ weight $(\mathrm{kg}) /$ height $^{2}(\mathrm{~m})$.

b Body esteem $=$ Physical Appearance subscale of the SPPC (Harter, 1985; Dutch translation: Veerman et al., 1997).

${ }^{\mathrm{c}}$ EDE - restraint child = Restraint subscale of the child Eating Disorder Examination completed by the child (Fairburn \& Cooper, unpublished manuscript; Dutch translation: Decaluwé \& Braet, unpublished manuscript).

${ }^{\mathrm{d}}$ EDE - restraint parent $=$ Restraint subscale of the child Eating Disorder Examination completed by the parent about the child.

point scale. Higher scores reflect more appetite and more hunger. Salivary flow was measured with two small cotton dental rolls (Hartman). The dental rolls were placed between the cheek and lower gum on the left and right side and each saliva collection time was $1 \mathrm{~min}$. The weight of the dental rolls in a small plastic box was registered before and after the saliva was collected (Mettler Toledo balance).

\subsubsection{Body esteem}

Body esteem was measured with the Physical Appearance subscale of the Self-Perception Profile for Children (SPPC, Harter, 1985; Dutch translation: Veerman, Straathof, Treffers, Van den Bergh, \& ten Brink, 1997). The 36-item SPPC measures perceived competence as part of one's self-esteem and is related to five specific domains, such as school, sport, and physics, and a sixth subscale measures global self-worth. Higher scores mean higher perceived competence for the scored domain. The mean internal consistency of the Dutch Scale is .73 and the mean stability (test-retest) is .76 (Veerman et al., 1997). In the present study, the scores on the Physical Appearance subscale were used as an index of body esteem. Lower scores on the Physical Appearance subscale reflect lower body esteem.

\subsubsection{Restrained eating}

The intention to restrain food intake was measured by the Restraint subscale of the Eating Disorder Examination (EDE, Fairburn \& Cooper, 1993). The five items were exactly copied from an unpublished Dutch version of the Child EDE (Decaluwé \& Braet, unpublished manuscript). To prevent that the children became aware that their eating style was of particular interest, the five restraint items were interspersed within a 34-item interview that was announced as a lifestyle interview. The interview included habits like how often they work at a computer, at what time they go to bed, whether they read often, and if they play sports. The restraint items all asked over the past four weeks: "Over the past four weeks (1) 
...have you deliberately been trying to cut down on what you eat, even if you haven't managed to do this? (2) ... have there been any days when you have not eaten anything for most (8 hours) of the day? (3) ... have you wanted your tummy to be empty - I mean not to have anything in it at all? (4) ... have you tried not to eat any foods that you like, even if you haven't managed this? And (5) ... have you tried to stick to certain definite rules about your eating; for example, only allowing yourself a certain amount of food, or a certain number of calories, or rules about what you should eat or when you should eat? Each restraint item was scored on a $0-6$ intensity or frequency scale and the total restraint score was determined by calculating the mean score, thus ranging from 0 to 6; higher scores reflecting a more restrained eating style. To cross-validate the restraint scores, a parent of the child was also interviewed on the restraint of the child.

\subsubsection{Mood}

Mood was measured on a nine-point scale with five cartoon faces, identical to the measurement of appetite and hunger. Instead of asking for appetite and hunger, "how do you feel now" was asked.

\subsection{Manipulations and taste test}

\subsubsection{Taste test}

The participants participated three times in a taste test; during 3 weeks, they participated once a week, each week on the same day of the week and at the same time of day. During the taste test, the participants were presented with seven large dishes with sweet and salty snacks: M\&M's (about $1100 \mathrm{~g} ; 483 \mathrm{kcal} / 100 \mathrm{~g}$ ), sugar peanuts (about $950 \mathrm{~g} ; 520 \mathrm{kcal} / 100 \mathrm{~g}$ ), small pieces of cake (about $750 \mathrm{~g} ; 403 \mathrm{kcal} / 100 \mathrm{~g}$ ), pieces of Milky Way (about $750 \mathrm{~g} ; 447 \mathrm{kcal} / 100$ g), crisps (about $550 \mathrm{~g} ; 550 \mathrm{kcal} / 100 \mathrm{~g}$ ), and savory nuts (about $800 \mathrm{~g} ; 520 \mathrm{kcal} / 100 \mathrm{~g}$ ). The child was invited to taste the foods and to complete a questionnaire on the taste of all the food items. Each taste test was preceded by one of the three following manipulations: (a) eating a preload, (b) exposure to the smell of the food without eating, and (c) playing (with Lego or drawing/colouring). The order of manipulations was counterbalanced.

\subsubsection{Preload}

Participants were given a preload of the taste test: $5 \mathrm{~g}$ M\&M's $(24.2 \mathrm{kcal}), 5 \mathrm{~g}$ sugar peanuts $(26 \mathrm{kcal}), 5 \mathrm{~g}$ cake $(20.2 \mathrm{kcal}), 5 \mathrm{~g}$ Milky Way $(22.4 \mathrm{kcal}), 5 \mathrm{~g}$ crisps $(27.5 \mathrm{kcal})$, and $5 \mathrm{~g}$ savory nuts $(26 \mathrm{kcal})$. Together, the preload weighed $30 \mathrm{~g}$ and consisted of $146 \mathrm{kcal}$. The participants were asked to eat it all within $10 \mathrm{~min}$. All participants ate the entire preload.

\subsubsection{Exposure}

During the exposure, participants intensely smelled large amounts of food on dishes for 10 min. The same dishes and amounts of food used in the taste test were used for the exposure. A dish was put right under the nose, and the participant was instructed to intensely smell the food. During the $10 \mathrm{~min}$ of exposure, the experimenter modeled and stimulated the participants to intensely smell each food item, without eating it (response prevention). 


\subsubsection{Control}

In the control condition, participants were not exposed to food cues but were invited to play with Lego or to draw/colour during $10 \mathrm{~min}$.

\subsection{Procedure}

Participants came to the laboratory with one of their parents. In the first session, the procedure of the experiment was explained and the child's height and weight were determined. The second author interviewed the child on lifestyle and restrained eating (see Assessment), while the third author interviewed the parent in an adjacent room. After the interview, the child completed the Dutch version of the SPPC and the parent signed an informed consent to be sure that their children were permitted to taste snacks containing fat and sugar. Then the parent and child were joined and appointments for the taste tests were made. The child was instructed not to eat anything within two hours before participation in the taste test. In the second, third, and fourth sessions, the manipulations and taste tests were done. During the manipulations and taste tests, the children were in the laboratory with the experimenter and the parent waited in an adjacent room.

In each taste test session, the child first completed the subjective state scales (appetite, hunger, mood) and saliva flow was measured without any food stimuli present. Then the manipulation took place (preload, exposure, or control) for $10 \mathrm{~min}$. During the manipulation, the experimenter was in the laboratory with the child. After the manipulation, the subjective states and saliva flow were measured again, with the food stimuli still present in the exposure condition. Then the taste test took place; the preweighed dishes with food were placed on the table in front of the child. The child was instructed to taste as much of the food as needed or wanted to complete a taste questionnaire and to wait for the experimenter after finishing the questionnaire. Then the experimenter left the laboratory for $15 \mathrm{~min}$. Completing the questionnaire took about $7 \mathrm{~min}$. After the taste test was finished, the second experimenter took away the remaining food and reweighed it. After participation in the third taste test, the child and the parent were thanked for participation; the child received a present and the parent was given euro 18 .

\section{Results}

Hypothesis 1: Overweight children show more cue reactivity after confrontation with food cues, i.e., they report more appetite/hunger and show increased salivary flow after eating a tasty preload and smelling tasty food than after a neutral cue.

Because Pearson's product-moment correlations between hunger and appetite were highly significant $(r=.81)$, it was decided to restrict cue reactivity measures to appetite and salivation. Table 2 shows the appetite and salivation responses for each group before and after the manipulations. For each dependent variable (appetite and salivation), a 2 (Group: overweight vs. normal weight) $\times 2$ (Time: before vs. after manipulation) $\times 3$ (Condition: preload vs. 
Table 2

Appetite ratings, salivary flow, and mood ratings of overweight $(n=16)$ and normal-weight $(n=15) 8$-12-yearold children before and after the manipulations: eating a preload, exposure to the intense smell of tasty food, and playing

\begin{tabular}{|c|c|c|c|c|c|c|c|c|c|c|c|c|}
\hline & \multicolumn{4}{|c|}{ Eating a preload } & \multicolumn{4}{|c|}{ Exposure to smell } & \multicolumn{4}{|c|}{ Control: playing } \\
\hline & \multicolumn{2}{|c|}{ Overweight } & \multicolumn{2}{|c|}{ Normal weight } & \multicolumn{2}{|c|}{ Overweight } & \multicolumn{2}{|c|}{$\underline{\text { Normal weight }}$} & \multicolumn{2}{|c|}{ Overweight } & \multicolumn{2}{|c|}{ Normal weight } \\
\hline & Before & After & Before & After & Before & After & Before & After & Before & After & Before & After \\
\hline Appetite & $\begin{array}{l}6.8 \\
(2.0)\end{array}$ & $\begin{array}{l}6.1 \\
(2.7)\end{array}$ & $\begin{array}{l}7.9 \\
(1.4)\end{array}$ & $\begin{array}{l}7.7 \\
(1.1)\end{array}$ & $\begin{array}{l}7.0 \\
(2.0)\end{array}$ & $\begin{array}{l}7.5 \\
(2.0)\end{array}$ & $\begin{array}{l}8.0 \\
(1.1)\end{array}$ & $\begin{array}{l}8.5 \\
(0.6)\end{array}$ & $\begin{array}{l}6.6 \\
(2.1)\end{array}$ & $\begin{array}{l}7.1 \\
(2.1)\end{array}$ & $\begin{array}{l}7.7 \\
(1.5)\end{array}$ & $\begin{array}{l}8.0 \\
(1.4)\end{array}$ \\
\hline $\begin{array}{l}\text { Salivary } \\
\text { flow (mg) }\end{array}$ & $\begin{array}{l}0.48 \\
(0.2)\end{array}$ & $\begin{array}{l}0.62 \\
(0.4)\end{array}$ & $\begin{array}{l}0.48 \\
(0.3)\end{array}$ & $\begin{array}{l}0.5 \\
(0.4)\end{array}$ & $\begin{array}{l}0.5 \\
(0.3)\end{array}$ & $\begin{array}{l}0.59 \\
(0.4)\end{array}$ & $\begin{array}{l}0.52 \\
(0.3)\end{array}$ & $\begin{array}{l}0.6 \\
(0.4)\end{array}$ & $\begin{array}{l}0.65 \\
(0.4)\end{array}$ & $\begin{array}{l}0.58 \\
(0.3)\end{array}$ & $\begin{array}{l}0.52 \\
(0.4)\end{array}$ & $\begin{array}{l}0.51 \\
(0.4)\end{array}$ \\
\hline Mood & $\begin{array}{l}7.6 \\
(1.5)\end{array}$ & $\begin{array}{l}7.8 \\
(1.6)\end{array}$ & $\begin{array}{l}8.3 \\
(0.9)\end{array}$ & $\begin{array}{l}7.9 \\
(1.3)\end{array}$ & $\begin{array}{l}7.8 \\
(1.6)\end{array}$ & $\begin{array}{l}8.0 \\
(1.3)\end{array}$ & $\begin{array}{l}8.0 \\
(1.1)\end{array}$ & $\begin{array}{l}8.3 \\
(0.8)\end{array}$ & $\begin{array}{l}7.8 \\
(1.2)\end{array}$ & $\begin{array}{l}7.9 \\
(1.2)\end{array}$ & $\begin{array}{l}8.3 \\
(0.8)\end{array}$ & $\begin{array}{l}8.0 \\
(1.1)\end{array}$ \\
\hline
\end{tabular}

Mean scores are given with standard deviations in parentheses.

exposure to smell vs. control) ANOVA with time and condition being within-subject variables and group a between-subject variable was run. Significant interactions were further examined with contrast analyses. For appetite, the ANOVA showed a significant main effect for group $[F(1,29)=4.2, P<.05]$, a main effect for condition $[F(2,28)=6.0, P<.01]$, and a significant Condition $\times$ Time interaction $[F(2,28)=8.3, P=.001]$. No other significant main or interaction effects were found. Contrast analyses showed that the overweight children reported less appetite than normal-weight children $(P<.05)$. Furthermore, they showed that appetite was significantly higher in the exposure condition than in the preload condition $(P<.005)$ and marginally significantly higher than in the control condition $(P<.08)$. Judging from the means, the Condition $\times$ Time interaction points to a significant difference between the appetite change in the preload condition versus the appetite change in the control and exposure condition; in the control and exposure condition, appetite increased after the manipulation, whereas appetite decreased for both groups after the preload.

For salivation response, the ANOVA showed no significant main or interaction effects at all, meaning that the manipulations did not significantly influence salivary flow, and that the overweight and normal-weight groups did not differ significantly in salivary response.

All in all, the overweight children reported less appetite than normal-weight children, and no evidence for increased cue reactivity in overweight participants after being confronted with disinhibiting stimuli was found. While exposure led to increased appetite and the preload to decreased appetite, the effect was the same for both the overweight and normal-weight groups.

Hypothesis 2: Eating a preload and being exposed to food cues increase the caloric intake of overweight children.

Fig. 1 shows the caloric intake of normal-weight and overweight children in the three conditions. The intake data were not normally distributed and were therefore log-transformed. The analyses were done on the log-transformed data in a multivariate $3 \times 2$ (Condition $\times$ Group) ANOVA, with condition being a within-subject variable and group a 


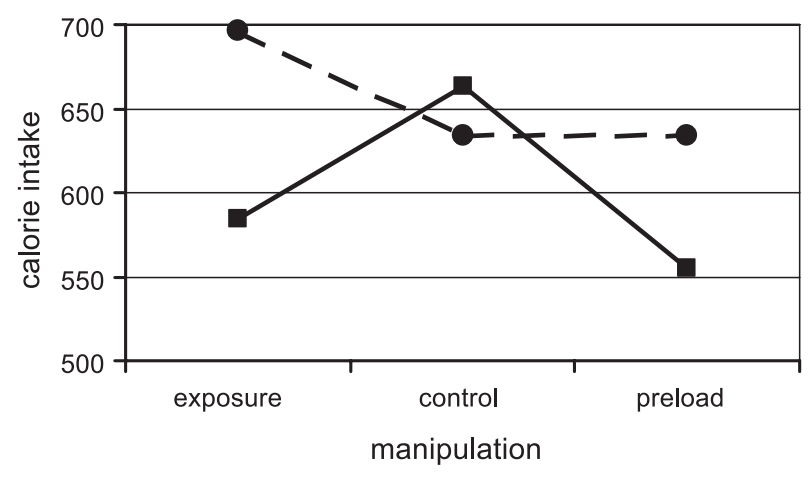

Fig. 1. Mean kilocalorie intake of normal weight $(n=15)$ and overweight $8-12$-year-old children $(n=16)$ after forced consumption of a preload (preload condition), after $10 \mathrm{~min}$ of intense exposure to the smell of tasty food (exposure condition), and after 10 min of playing (control condition).

between-subject variable. The analysis showed neither a main effect for group $[F(1,29)<1]$, nor a main effect for condition $[F(2,28)=1.6, \mathrm{NS}]$. There was, however, a significant Group $\times$ Condition interaction $[F(2,28)=3.97, P=.03]$. Introducing gender and restraint as covariates did not change the results. Contrast analyses with the control condition as reference showed that overweight children did not reduce their intake after eating a preload $(F<1)$, whereas normal-weight children ate significantly less after consuming a preload $(F=5.7$, $P=.03)$. After the intense smelling of tasty food during the exposure, the overweight children tended to eat more $(F=3.3, P=.09)$, whereas the normal-weight children reduced their intake significantly after being exposed to the smell of tasty food $(F=6.2, P<.03)$.

The data thus show that overweight children do not regulate their food intake after a preload, whereas normal-weight children do. Furthermore, they show that normal-weight children eat significantly less after intense exposure to the smell of tasty food, whereas overweight children tend to eat even more after the exposure.

Hypothesis 3: The increased intake of overweight children is related to increased cue reactivity.

Pearson's product-moment correlations were calculated for the changes in appetite and salivary flow (the difference between baseline measurement and the measurement after the manipulation) on the one hand and caloric intake on the other hand. No significant correlations between appetite changes and caloric intake were found. The data showed however marginally significant relations between salivary flow increase and caloric intake in the exposure condition $(r=.3, P=.09)$ and the control condition $(r=.33, P=.07)$, meaning that in these conditions an increase in salivation was related to an increase in food intake. Further analyses showed that in particular, the overweight participants showed a highly significant correlation between caloric intake and salivary flow after exposure $(r=.62, P=.01)$, whereas this relation was almost absent in the normal-weight group $(r=.05, \mathrm{NS})$. 
Hypothesis 4: Restraint, body esteem, and mood are related to caloric intake after disinhibitors such as smelling and tasting tasty food; it is expected to find a positive relation between restraint and intake (more restraint, more intake), a negative relation between body esteem and caloric intake (lower body esteem, more intake), and a negative relation between mood and caloric intake (lower mood, more intake).

Pearson's product-moment correlations were calculated between caloric intake on the one hand, and restraint, body esteem, and mood on the other hand. The data showed no significant relations between restraint and caloric intake $(r=-.15)$, mood and caloric intake $(r=.18)$, body esteem and caloric intake $(r=.17)$ after a preload, no significant relations between restraint and caloric intake $(r=-.12)$, mood and caloric intake $(r=-.06)$, body esteem and caloric intake $(r=-.02)$ after exposure, and no significant relations between restraint and caloric intake $(r=-.11)$, mood and caloric intake $(r=.19)$, body esteem and caloric intake $(r=-.07)$ after the control manipulation. It is concluded that neither restraint nor body esteem and mood were related to the amount of food intake in overweight and normal-weight children.

\section{Discussion}

The main question of the present study was whether overweight children would show increased cue reactivity and food intake after eating a tasty preload and after the intense smelling of tasty food. It was also examined whether cue reactivity, restraint, mood, and body esteem were related to caloric intake. The data indeed show that overweight children do not regulate their food intake like normal-weight children do. Normal-weight children eat less after having eaten a preload and after intense exposure to the smell of tasty food, whereas the overweight children do not lessen their intake after confrontation with both food cues. They even eat marginally more after the intense exposure to the smell of tasty food.

Although the overweight and normal-weight children showed dissimilar eating patterns after the introduction of tasty food cues, no evidence for more cue reactivity in overweight participants after being confronted with disinhibiting stimuli was found. Though they did not show more reactivity, the correlational data support the idea that cue reactivity is related to intake only in the overweight children; a strong correlation between the exposure-elicited salivary flow and caloric intake in overweight children was found, and not in the normalweight ones. No relations between caloric intake on the one hand and restraint, body esteem, and mood on the other hand were found.

What do these data mean? First of all, they show that overweight children eat normal amounts when tempting food cues are lacking. But when the overweight children are tempted by the taste or intense smell of tasty food, they show abnormal eating patterns; they do not eat less after these cues like normal-weight children do and thus fail to regulate their intake. In other words, overweight children are more vulnerable to triggers of overeating.

What makes overweight children more vulnerable to triggers of overeating? It was hypothesized that their vulnerability would follow from a learned association between the 
tempting cues and increased intake. Although the cues did not elicit increased cue reactivity (appetite, salivation) in the overweight group, the cue-elicited salivary response of the overweight sample was significantly related to their increased intake. Clearly, the cues elicited reactivity-related overeating in the overweight sample and not in the normal-weight sample, a finding that supports the idea that classically conditioned associations between cues that predict food intake (smell, taste) and actual eating behavior are stronger in overweight than in normal-weight children.

A point of concern is that the standardized preload might have worked as a prime in the overweight children, whereas it might have produced sensory-specific satiety in the normalweight children. When a food is eaten to satiety, its reward value decreases to zero, and this is accompanied by a decreased pleasantness of the taste and smell of the food, i.e., sensoryspecific satiety (Rolls \& Rolls, 1997). The preload was the same as the food used in the taste test, and although the amount of kilocalories of the preload was quite low for everybody, the energy needs of, e.g., a lean 8-year-old are lower than the energy needs of an overweight 12year-old. The small preload might have primed the overweight children whereas it might have led to some sensory-specific satiety in the normal-weight children.

Interesting though is that the exposure to food cues-without eating a preload-led to the same eating pattern. It is particularly exciting that normal-weight children ate less after a 10-min period of intense smelling of the tasty food without eating it. In our lab, we have found the same eating pattern earlier, in normal-weight unrestrained eating females (Jansen \& van den Hout, 1991); after a 10-12-min period of intense smelling tasty food without eating it, unrestrained normal-weight females ate significantly less than without having smelled the food. The present sample of normal-weight children showed identical behavior. Sensory-specific satiety might also explain normal people's eating behavior after the intense smelling of food. Could it be that normal-weight and unrestrained samples reach satiety earlier through the intense smelling of food than overweight or restrained eating samples? It has been documented that sensory-specific satiety does not require food to enter the gastrointestinal system (Rolls \& Rolls, 1997). Also, chewing the food without swallowing it can produce sensory-specific satiety, and even more important in the light of the present findings is the fact that a 5 -min period of olfactory stimulation alone (i.e., smelling) produced decreased pleasantness of the smell of the food, which is called olfactory sensory-specific satiety (Rolls \& Rolls, 1997). Moreover, it was found that food intake is controlled by a sensory-specific decrease in neural activity in the orbitofrontal cortex, which is independent of gut feedback from the food entering the stomach (O'Doherty et al., 2000). The implication is, according to the authors, that the intake of foods can be limited by presenting the same odor for a period of at least several minutes, and that is exactly what we found in normal-weight unrestrained eating adults and the present sample of normal-weight children. The smell of the food may have induced some satiety, like the preload did, leading to decreased food intake in the normal-weight children. The present data also show that overweight children did not reach satiety, not even after a 10 -min period of intense smelling. They even showed a tendency to eat more after smelling than without smelling, which makes it of great interest to measure whether there is a slowing down of the sensory-specific 
decrease in neural activity in people that show a tendency to overeat. Indirect post hoc evidence for this idea is given in our studies on the extinction of craving in binge eaters; binge eaters show increased craving after they started smelling their binge food (without eating it), and the top of their craving is after about $20 \mathrm{~min}$, after which craving gradually declines (see, e.g., Jansen, Broekmate, \& Heijmans, 1992; Jansen, Elgersma, Nederkoorn, \& Smeets, 2002).

Relating these findings to the cue reactivity model, it might be hypothesized that tasting or intense smelling of palatable food works as a prime that elicits cue reactivity especially in participants that are used to eat after being confronted with these cues, like overweight children. The same cues do not elicit reactivity in normal participants that do not always eat after confrontation with these cues; they show sensory-specific satiety responses. Note that the priming cues will elicit reactivity as long as they are reliable predictors of intake. The model predicts that the cue reactivity will lead to overeating until the cue-intake bond is broken by prolonged and repeated nonreinforced exposure to the cues. During cue exposure, the participant is exposed to the cues (smell, taste) and prevented from intake, which at last leads to reduced reactivity and craving (Jansen, 1998; Jansen et al., 2002). In the light of the present data, cue exposure with response prevention might be a promising new treatment strategy for child obesity.

It is remarkable that the present sample of overweight children showed an eating pattern that is also found in normal-weight but highly restrained eating females. In many studies, it has been documented that restrained eating females counter-regulate (Herman \& Polivy, 1980) or fail to regulate (Jansen, Merckelbach, Oosterlaan, Tuiten, \& van den Hout, 1988) their intake after a preload. The current explanation for the counter-regulation and nonregulation of highly restrained eaters is that it is caused by their restrained eating style (e.g., Herman \& Polivy, 1984). Although it certainly might be concluded from most data on restraint and counter-regulation that a restrained eating style and counter-regulation are related, it should be noted that most of these studies are quasi-experimental in nature (restraint is not manipulated) and thus do not say anything about the causal relation between restraint and the failure to regulate. In the present study, restraint was not at all related to caloric intake. It is possible that the present sample of young overweight children did not yet restrain their food intake. Perhaps they will become more or less successful restrained eaters trying to reduce their excessive intake when they grow older and become more conscious of the negative physical and social consequences of being overweight. If that is the case, their future restrained eating style follows a tendency to overeat and reflects a fight against eating more than needed instead of eating less than needed, a possibility that Lowe (1993) discussed years ago.

All in all, it might be concluded that overweight children fail to regulate their food intake when they are confronted with temptations like the intense smell and taste of appetizing food. Their overeating is not related to psychological factors like mood, self-esteem, and a restrained eating style, but strongly correlates with induced salivation flow. A fascinating idea that needs to be tested is whether the failure of overweight children to regulate intake is paralleled by a slowing down of the sensory-specific decrease in neural activity in the orbitofrontal cortex, which is responsible for olfactory sensory-specific satiation. 


\section{Acknowledgements}

Thanks are expressed to Fren Smulders for his useful comments on an earlier draft of this paper.

\section{References}

Braet, C., \& van Strien, T. (1997). Assessment of emotional, externally induced and restrained eating behaviour in nine to twelve-year-old obese and non-obese children. Behaviour Research and Therapy, 35, 863-873.

Decaluwé, V., \& Braet, C. Dutch translation of the Child Eating Disorder Examination, authored by Fairburn, C. G. and Cooper, Z. (unpublished manuscript).

Dietz, W. H. (1995). Childhood obesity: Prevalence and effects. In K. D. Brownell, \& C. G. Fairburn (Eds.), Eating disorders and obesity: A comprehensive handbook (pp. 438-440). New York: Guilford Press.

Fairburn, C. G., \& Cooper, Z. (1993). The Eating Disorder Examination (12th ed.). In C. G. Fairburn, \& G. T. Wilson (Eds.), Binge eating: Nature, assessment, and treatment (pp. 317-360). New York: Guilford Press.

Fairburn, C. G., Marcus, M. D., \& Wilson, G. T. (1993). Cognitive-behavioral therapy for binge eating and bulimia nervosa: A comprehensive treatment manual. In C. G. Fairburn, \& G. T. Wilson (Eds.), Binge eating: Nature, assessment, and treatment (pp. 361-404). New York: Guilford Press.

Fedoroff, I. C., Polivy, J., \& Herman, C. P. (1997). The effect of pre-exposure to food cues on the eating behavior of restrained and unrestrained eaters. Appetite, 28, 33-47.

Harter, S. (1985). Manual for the Self-Perception Profile for Children. Denver: University of Denver.

Herman, C. P., \& Polivy, J. (1980). Restrained eating. In A. Stunkard (Ed.), Obesity (pp. 208-225). Philadelphia: Saunders.

Herman, C. P., \& Polivy, J. (1984). A boundary model for the regulation of eating. In A. J. Stunkard, \& E. Stellar (Eds.), Eating and its disorders (pp. 141-156). New York: Raven Press.

Hirasing, R. A., Fredriks, A. M., van Buuren, S., Verloove-Vanhorick, S. P., \& Wit, J. M. (2001). Toegenomen prevalentie van overgewicht en obesitas bij Nederlandse kinderen en signalering daarvan aan de hand van internationale normen en nieuwe referentiediagrammen. Nederlands Tijdschrift voor Geneeskunde, 27, $1303-1308$.

Jansen, A. (1998). A learning model of binge eating: Cue reactivity and cue exposure. Behaviour Research and Therapy, 36, 257-272.

Jansen, A., Broekmate, J., \& Heijmans, M. (1992). Cue exposure vs. self-control in the treatment of binge eating: A pilot study. Behaviour Research and Therapy, 30, 235-241.

Jansen, A., Elgersma, H., Nederkoorn, Ch., \& Smeets, T. (2002). What makes treatment of Bulimia Nervosa successful? Paper presented at the European Association for Cognitive and Behavior Therapies. Maastricht, 18-21 September 2002.

Jansen, A., Merckelbach, H., Oosterlaan, J., Tuiten, A., \& van den Hout, M. (1988). Cognitions and self-talk during food intake of restrained and unrestrained eaters. Behaviour Research and Therapy, 26, 393-398.

Jansen, A., \& Van den Hout, M. (1991). On being led into temptation: 'Counterregulation' of dieters after smelling a 'preload'. Addictive Behaviors, 5, 247-253.

Karhunen, L. J., Lappalainen, R. I., Vanninen, E. J., Kuikka, J. T., \& Uusitupa, M. I. J. (1997). Regional cerebral blood flow during food exposure in obese and normal-weight women. Brain, 120, 1675-1684.

Laessle, R. G., Uhl, H., \& Lindel, B. (2001). Parental influences on eating behavior in obese and nonobese preadolescents. International Journal of Eating Disorders, 30, 447-453.

Lowe, M. R. (1993). The effects of dieting on eating behavior: A three-factor model. Psychological Bulletin, 114, $100-121$.

Mattes, R. D. (1997). Physiological responses to sensory stimulation by food: Nutritional implications. Journal of the American Dietetic Association, 97, 406-412. 
Nederkoorn, C., Smulders, F., \& Jansen, A. (2000). Cephalic phase responses, craving and food intake in normal subjects. Appetite, 35, 45-55.

O’Doherty, J., Rolls, E. T., Francis, S., Bowtell, R., McGlone, F., Kobal, G., Renner, B., \& Ahne, G. (2000). Sensory-specific satiety-related olfactory activation of the human orbitofrontal cortex. NeuroReport, 11, $893-897$.

Rodin, J. (1985). Insulin levels, hunger, and food intake: An example of feedback loops in body weight regulation. Health Psychology, 4, 1-24.

Rogers, P. J., \& Hill, A. J. (1989). Breakdown of dietary restraint following mere exposure to food stimuli: Interrelationships between restraint, hunger, salivation, and food intake. Addictive Behaviors, 14, 387-397.

Rolls, E. T., \& Rolls, J. H. (1997). Olfactory sensory-specific satiety in humans. Physiology and Behavior, 61, $461-473$.

Rosen, J. C. (1996). Improving body image in obesity. In J. K. Thompson (Ed.), Body image, eating disorders, and obesity. An integrative guide for assessment and treatment (pp. 425-440). Washington, DC: American Psychological Association.

Van Wieringen, J. C., \& Roede, M. J. (1985). Growth diagrams 1980. Netherlands third nation-wide survey. Tijdschrift voor Sociale Gezondheidszorg (Dutch Journal of Social Health Care), 63, 1-34 (Supplement).

Veerman, J. W., Straathof, M. A. E., Treffers, Ph. D. A., van den Bergh, B. R. H., \& ten Brink, L. T. (1997). Competentiebelevingsschaal voor kinderen. Lisse: Swets and Zeitlinger.

Visscher, T. L., Kromhout, D., \& Seidell, J. C. (2002). Long-term and recent time trends in the prevalence of obesity among Dutch men and women. International Journal of Obesity and Related Metabolic Disorders, 9, $1218-1224$.

Vögele, C., \& Florin, I. (1997). Psychophysiological responses to food exposure: An experimental study in binge eaters. International Journal of Eating Disorders, 21, 147-157.

Wardle, J. (1990). Conditioning processes and cue exposure in the modification of excessive eating. Addictive Behaviors, 15, 387-393.

Wegner, K. E., Smyth, J. M., Crosby, R. D., Wittrock, D., Wonderlich, S. A., \& Mitchell, J. E. (2002). An evaluation of the relationship between mood and binge eating in the natural environment using ecological momentary assessment. International Journal of Eating Disorders, 32, 352-361.

Woods, S. C. (1991). The eating paradox: How we tolerate food. Psychological Review, 4, 488-505. 